\title{
Judicialização da medicina no acesso a medicamentos: reflexões bioéticas
}

Thereza Cristina de Arruda Salomé D’Espíndula

\section{Resumo}

O artigo trata da judicialização da medicina voltada ao acesso a medicamentos, situação persistente que causa agravos ao sistema público de saúde. Objetiva apresentar os pontos básicos desta prática realizando reflexão bioética, mediante revisão bibliográfica e sistematização do material levantado. Os resultados mostram que a judicialização da medicina vem tomando cada vez mais vulto e não terá condições de sustentar-se por muito tempo. A bioética, multidisciplinar, pode sugerir algumas soluções. Conclui-se que as decisões do Judiciário deveriam contemplar a complexidade da vida humana, não apenas garantindo medicamentos. Seria importante a comunicação entre a saúde e a Justiça para discussões e elaborações de pareceres, bem como refletir sobre o significado individual do pedido e obtenção das medicações por via judiciária. Isto poderia revelar questões pessoais e qualidade de vida, preservando a ambas.

Palavras-chave: Assistência à saúde. Qualidade de vida. Ética. Vulnerabilidade em saúde. Bioética.

\section{Resumen}

\section{Judicialización de la medicina en el acceso a medicamentos: reflexiones bioéticas}

El artículo trata de la judicialización de la medicina en el acceso a los medicamentos, situación persistente que causa empeoramiento al sistema de salud pública. Presentar puntos básicos de esta práctica realizando una reflexión bioética mediante revisión bibliográfica y sistematización del material recogido. Los resultados permiten observar que la judicialización de la medicina está creciendo y no tendrá condiciones de sostenerse por mucho tiempo. La bioética, multidisciplinaria, puede sugerir algunas soluciones. Se concluye que las decisiones del Judicial deberían contemplar la complejidad de la vida humana, no sólo garantizando medicamentos. Sería importante la comunicación entre la salud y la Justicia para discusiones y elaboraciones de opiniones, así como reflejar acerca del significado individual del pedido y obtención de las medicinas a través del judicial. Esto podría revelar asuntos personales y de calidad de vida, preservando a ambas.

Palabras-clave: Prestación de atención de salud. Calidad de vida. Ética. Vulnerabilidad en salud. Bioética.

\begin{abstract}
Judicialization of medicine in the access to drugs: bioethical reflections

This article discuse about judicialization of medicine in the access to drugs, a persistent health status that causes injuries to the public system of health. We exposed the basic points to such practice to provide a bioethical discussion of the processes, through bibliographic revision and the systematization of the collected material. It is possible to note that the judicialization of medicine has increasingly been taking relevance and it will no longer be able to be supported. The multidisciplinary Bioethics may suggest some solutions. It is concluded that Judiciary decisions would contemplate the complexity of human life, not just assuring drugs. It would be important the communication between health and justice for discussions and opinion elaboration, as well as discussing on the individual meaning of the request and obtaining medications by judiciary means. This could reveal personal issues and quality of life, by preserving both ones.

Key words: Delivery of health care. Quality of life. Ethics. Health vulnerability. Bioethics.
\end{abstract}

1. Mestre therezapsi@gmail.com - Faculdades Pequeno Príncipe, Curitiba/PR, Brasil.

\section{Correspondência}

Avenida Iguaçu, 333 Rebouças CEP 80230-020. Curitiba/PR, Brasil.

Declara não haver conflito de interesse. 
Como situação persistente na saúde e causa de agravos ao bom andamento do sistema público de saúde, a judicialização da medicina, no que concerne ao acesso a medicamentos, apresenta alguns pontos importantes para discussão. Nesse particular enfoque, a bioética, com sua multidisciplinaridade, pode ser de grande auxílio para compreender o fenômeno e sugerir algumas soluções.

Pretendeu-se iniciar pela conceituação da judicialização da medicina, bem como sucinta explicação acerca do fornecimento de medicamentos por meio do Sistema Único de Saúde (SUS) e os tipos de solicitação acolhidos pelo Judiciário. Na sequência, serão apresentados os atores deste processo, quais sejam, o SUS, o direito, a medicina e os usuários dos serviços de saúde. Prossegue-se apontando alguns aspectos bioéticos e, a partir daí, uma discussão.

\section{Conceitos básicos}

\section{Judicialização da medicina}

O uso das expressões judicialização da medicina ou judicialização da saúde vêm se tornando corriqueiros pois cada vez mais indivíduos recorrem à Justiça para obter aportes necessários para seus tratamentos. Assim, essas expressões apontam para problemas no acesso a bens e serviços da área da saúde, cirurgias não previstas pelo SUS, responsabilidade médica, liberação de leitos de unidades de terapia intensiva (UTI), medicamentos, dentre muitos outros, por intermédio de ações judiciais. Ainda que questionável, a demanda se baseia inicialmente na Carta Magna, que no artigo $6^{\circ}$ define saúde como direito social e no artigo 196 garante igual acesso de todos a ela. A Lei Orgânica da Saúde (Lei 8.080/90) consolidou no Brasil a defesa por melhores condições de saúde e de vida, pautada num sistema de atendimento público com qualidade e universalidade ${ }^{1}$.

A judicialização da medicina - que no presente artigo restringe-se à obtenção de medicamentos acaba por gerar uma rede de tensão entre os poderes Judiciário, Executivo e Legislativo. O Judiciário, porque tem a função de fazer cumprir as leis e, neste caso, concretizar o acesso aos medicamentos solicitados; o Executivo, pois estabelece e executa as políticas públicas destinadas a garantir o cumprimento das leis; e o Legislativo, do qual emanam as leis que permitem a todos o acesso à Assistência Farmacêutica (AF). Pedidos de medicamentos via Poder Judiciário têm se avolumado, gerando dificuldades na gestão, pois sua compra, bem como qualquer gasto, deve acompanhar uma execução orçamentária e financeira do ministério ao qual está vinculada (no caso, ao Ministério da Saúde).

Com uma demanda por saúde infinita e recursos finitos, a judicialização da medicina, no tocante aos pedidos de medicamentos, vem impondo certa iniquidade aos usuários, numa estrutura paralela, tendo em vista o desembolso monetário crescente para o atendimento de sua demanda; uma dificuldade na execução dos serviços; uma alocação irracional de recursos e, até mesmo, possíveis danos à saúde do paciente.

As políticas públicas do SUS são facilmente prejudicadas por esses gastos não programados ${ }^{2}$. Ao destinar uma cota para a $A F$, o Sistema não pode prever quantas ações judiciais serão atendidas, tampouco o valor monetário para cobrir essa demanda. Logo, se esses medicamentos representarem uma porcentagem muito alta, outros recursos terão que ser protelados ou cancelados. Entretanto, em locais onde a política de AF não se faz presente da forma esperada, a judicialização da medicina pode representar um caminho legítimo de reivindicação de direitos dos usuários.

A determinação judicial do fornecimento dos medicamentos pode ser ou não benéfica. Sem tempo para prévia avaliação da real necessidade, o juiz culmina por liberar o medicamento pleiteado, podendo ou não contribuir para uma melhoria da qualidade de vida do requerente em particular e da população assistida em geral. Tem como resultados positivos induzir a atualização de programas e protocolos de práticas terapêuticas. Como resultados negativos, em vários casos, uma precoce incorporação de medicamentos, visando reduzir as demandas judiciais, por vezes sem atender adequadamente aos critérios de eficácia, segurança e prioridades sanitárias.

\section{Fornecimento de remédios via SUS}

A garantia de acesso a medicamentos essenciais, prevista pela Política Nacional de Medicamentos (PNM) ${ }^{3}$, levanta a reflexão sobre o conceito relativo à essencialidade. Esse conceito envolve o desenvolvimento científico e tecnológico, a produção de medicamentos, a verificação de sua qualidade, a regulamentação sanitária, a reorientação da $\mathrm{AF}$ e o desenvolvimento e capacitação de recursos humanos para um melhor acesso aos medicamentos. Os medicamentos constantes da AF têm avaliação de eficiência e efetividade, além da relação custo-benefício, segurança e relevância pública; envolvem seleção, programação, aquisição, armazenamento, distribuição e utilização (prescrição, dispensação e uso). 
A Organização Mundial da Saúde (OMS) estabelece que cada país elabore sua própria lista de medicamentos essenciais para atender as necessidades da população. Deve haver critérios como eficácia e segurança dos fármacos, limitando ao mínimo o uso de medicamentos de eficácia não comprovada, que podem apresentar riscos. Também há a intenção de evitar a duplicidade de fármacos para uma mesma indicação clínica. Com base nessa proposta, o programa de AF preconiza uma forma de assistência, tendo a equidade como objetivo. Além dos medicamentos essenciais, há aqueles de dispensação excepcional, bem como programas de distribuição de medicamentos para doenças específicas (tuberculose, malária, diabetes etc.), de forma a atender diferentes demandas de saúde.

O fornecimento dos medicamentos é de competência dos municípios, dos estados ou da União e a gestão deveria facilitar sua aquisição. Porém, muitas vezes o medicamento reivindicado não integra as listas do SUS ${ }^{4}$ ou sequer recebeu liberação da Agência Nacional de Vigilância Sanitária (Anvisa) para sua comercialização. Tal fato propõe algumas questões básicas: seriam as listas do SUS falhas, ao ignorar a necessidade da inclusão de certos medicamentos? Teria a indústria farmacêutica interesse em que novos medicamentos fossem incorporados rapidamente? Ignorariam os médicos o normalizado pela AF? Seja como for, parece estar sendo atribuída ao SUS a mera função de fornecedor de medicamentos, quando seu papel deveria ser o de integrar assistência médica e farmacêutica.

\section{Remédios da lista do SUS}

Conforme Medeiros, Diniz e Schwartz (2013), seriam três as razões principais para que um medicamento não faça parte do dispensário regular do SUS. A primeira refere-se à administração e problemas de estocagem; a segunda diz respeito a não inclusão do medicamento nas listas de dispensação seja porque não se reconhece cientificamente a eficácia terapêutica do medicamento ou porque, apesar do reconhecimento científico, o trâmite de autorização pelo sistema de vigilância sanitária não foi concluído. A terceira razão é a recusa da distribuição em função da existência de potenciais substitutos com melhor relação custo-benefício (eficiência terapêutica), conhecida como a tese da racionalidade em saúde ${ }^{5}$.

A lista de medicamentos essenciais do SUS ${ }^{4}$ inclui medicamentos de alto, médio e baixo custo, não estando vinculada a valores monetários. Evidentemente, embora abarque grande quantidade e variedade de medicamentos, não cobre absolu- tamente todas as necessidades. Quando é preciso lançar mão de medicamentos ausentes das listas, devem ser verificadas as evidências científicas que justifiquem seu uso e, em caso positivo, fornecê-lo. Deve ser também verificado se não há alternativa terapêutica. Talvez haja medicamentos ausentes em hospitais e demais instituições de saúde, possivelmente por falhas de gerenciamento na AF. Também é possível que haja um desconhecimento das listagens oficiais de medicamentos.

$O$ registro de medicamentos no Brasil obedece a uma série de normas impostas pela Anvisa, independentemente do produto ter sido registrado em outros países. Dentre estas normas destacam-se a apresentação de relatórios técnicos com dados minuciosos acerca dos resultados de ensaios clínicos; da comprovação da eficácia e segurança; preço no país onde já há comercialização; registro no país de origem e outros, que, quando não apresentados, retardam ou dificultam a aprovação ${ }^{1}$.

\section{Remédios sem liberação da Anvisa}

Os pedidos de medicamentos sem registro na Anvisa ou com registro em trâmite causam transtornos, tendo em vista a dificuldade maior na aquisição e o risco para a saúde dos usuários. Também há que se considerar a hipótese de que já possa haver no mercado medicamento com a mesma indicação.

Pedidos de medicamentos sem registro podem também indicar algum tipo de pressão da indústria farmacêutica, tendo em vista ser o SUS um grande cliente. Muitas e repetidas ações para a aquisição de um mesmo medicamento sem registro podem forçar a Anvisa a liberá-lo com rapidez, sem as necessárias averiguações. Uma vez liberado, a indústria farmacêutica facilmente poderia ampliar seus lucros.

\section{Atores envolvidos}

\section{O Sistema Único de Saúde}

A gestão da saúde é a mais nobre missão dos governos democráticos e o seu reconhecimento como direito traz uma responsabilidade ética e legal da implantação de políticas e ações capazes de assegurar à população as ações de assistência à saúde. Todavia, há a possibilidade do cidadão, ao se sentir preterido por essas políticas, recorrer ao poder público para fazer valer essa obrigação do Estado e seu direito à saúde.

Gestores de saúde têm se mobilizado para compreender e avaliar melhor esse fenômeno, de- 
vido principalmente ao impacto financeiro que tais ações causam, a fim de que sejam tomadas medidas para a redução das demandas judiciais ${ }^{6}$. Assim, há necessidade de que sejam efetuados estudos, elaborados indicadores de monitoramento, realizado acompanhamento temporal e, ainda, efetuadas comparações em diferentes localidades.

As decisões na área da saúde são de cunho complexo, pois envolvem desde o financiamento até o uso racional de recursos, necessitando de bom planejamento prévio para a administração das ações. Regulamentos técnicos, protocolos e critérios científicos e epidemiológicos farão grande diferença na definição da melhor política de saúde. A judicialização da medicina interfere diretamente nessa organização, prejudicando a alocação racional de recursos e o planejamento das ações de saúde, que preconizam a universalidade, a integralidade e a equidade. Acabam por maximizar diferenças, haja vista que acolhem situações nas quais o indivíduo eventualmente não pertence à população mais vulnerável, possuindo esclarecimento e poder econômico suficiente para custear a intervenção de um advogado ${ }^{2}$.

Quando de doenças crônicas, que demandam recursos geralmente elevados e medicamentos a longo e médio prazos, as ações judiciais são ainda mais frequentes, conforme mostrou a literatura consultada ${ }^{1,2,6-9}$. Esse fato, por si só, pode representar a opção pela contratação de um advogado, pois a obtenção do medicamento representa benefício financeiro capaz de suplantar os gastos com honorários advocatícios.

Há que se atualizar constantemente as listas de medicamentos, visando garantir o acesso de todos a cada vez mais fármacos com segurança e eficácia garantidas, bem como forma de combater a judicialização contínua e intensa. Ações e decisões judiciais são consequência do amadurecimento na organização da sociedade por um lado e, por outro, das deficiências na administração pública. Na tentativa de evitar novos processos, a incorporação de medicamentos à rede pública deve ser mais bem compreendida, além de aperfeiçoada e agilizada ${ }^{1}$.

\section{Médicos e a medicina}

Igualmente sob a pressão do capitalismo e da sociedade de consumo, o médico consulta publicações especializadas e frequenta eventos científicos. Mas precisa estar atento às ações da mídia em favor da indústria farmacêutica, que usualmente está por trás dessa disseminação de conhecimento, quase sempre interessada em comercializar inovações terapêuticas, culminando por exercer alguma influência sobre seus padrões de prescrição.

Proibições e limitações recentes impostas às propagandas de novos fármacos têm gerado formas alternativas para a indústria farmacêutica divulgar seus produtos. A mídia e os congressos médicos, bem como artigos voltados para essa classe, têm sido excelentes e eficientes formas de atuação para alcançar seus objetivos. Igualmente, não faltam convites aos veículos de comunicação para dar voz a essas estratégias, fazendo as novidades científicas chegarem à população.

Também o desconhecimento acerca da PNM e respectivas listas de medicamentos pode levar à ação precipitada, em busca de um medicamento não padronizado, "de última geração", mas ainda sem evidências para prescrição ou utilização. Estudos concluem que a maioria das prescrições que chegam à Justiça é oriunda de hospitais universitários, que costumam avaliar novas tecnologias e tratamentos ${ }^{7-8}$.

Portadores de doenças crônicas tendem a recorrer ao Judiciário, numa ação individualizada em detrimento de uma questão coletiva. A classe médica acaba por enfatizar o critério do direito prioritário à saúde, desconsiderando que saúde envolve fatores sociais, econômicos e ambientais, além de ações e serviços integrais de promoção, proteção e recuperação, o que torna essencial o controle eficaz das informações trazidas pela indústria farmacêutica, bem como a correta avaliação da condição patológica do paciente, levando à adequada prescrição de medicamentos e solicitação de exames.

\section{Direito à saúde}

O Judiciário tem como característica só agir mediante a provocação de pessoas, físicas ou jurídicas, interessadas em reivindicar algo. Essa reivindicação ocorre de maneira individual, de modo a permitir que apenas um lado da ação saia vitorioso. Conflitos de natureza distributiva, que envolvem bens como o direito à saúde, estão sendo levados a ele; mas são questões coletivas excessivamente complexas para serem abordadas pelos órgãos de Justiça, tradicionalmente acostumados a lidar com critérios e mecanismos para decidir sobre conflitos bilaterais, apropriados ao exercício da justiça comutativa, não sendo adequados ao exercício da justiça distributiva e, como tal, não deveriam ser aplicados às decisões sobre bens providos pelo Estado. 
Dito de outra maneira, quando a questão em pauta é a saúde, em especial no que se refere ao fornecimento de medicamentos, o ganho de alguns pode significar a imediata lesão a outros. $O$ resultado seria uma perda ou um ganho para toda a sociedade; trata-se da alocação de recursos escassos ou indivisíveis e não de retribuição ou indenização entre duas partes. A saúde é um bem comum, um direito social e deve ser tratada de forma coletiva quando envolve a distribuição equitativa de recursos ${ }^{9}$.

Assim, tratar como se fosse uma questão entre duas partes, quando, na verdade, o conflito irá atingir a coletividade, é um dos limites às decisões judiciais que tratam de bens comuns ${ }^{9}$. Seria preciso ir além da relação processual, não apenas numa oposição bilateral paciente-Estado, mas também o mercado de fármacos e a comunidade científica. É primordial que o poder público exerça papel diferenciado nessas questões, pois as demandas sociais são dinâmicas e os conflitos existentes necessitam soluções voltadas para o futuro. Isso exige o exercício da visão em longo prazo, a qual talvez ainda não seja de costume praticar ${ }^{9}$. Ademais, a judicialização da medicina não pode vir a se tornar preocupação maior do que a própria efetividade dos serviços.

A forma rápida com que esse tipo de conflito levou o poder público a adotar uma posição frequente de deferimento vem mostrar que ainda não houve tempo, por parte deste, para se apareIhar melhor ante esses novos critérios de julgamento. Sem conhecimento dos elementos constantes das políticas públicas sobre medicamentos, não há como garantir a universalidade e a equidade, que levam a uma assistência tanto eficaz quanto segura à saúde de cada cidadão.

É bom lembrar que aquisições por via judicial e de caráter emergencial também podem favorecer fraudes. Medicamentos sem o devido registro na Anvisa ou fora das listas da AF podem indicar pressão velada, camuflando interesses outros que não o de verdadeiramente recuperar a saúde da população. Contudo, em casos de falta de medicamentos e/ou não cumprimento de protocolos clínicos, a judicialização constitui o meio mais ágil para o efetivo cumprimento desse direito.

Ainda que muitas das ações indiquem falhas da própria União como provedora da assistência, elas tendem a constituir estímulo à medicalização, falha no uso racional de medicamentos e obstáculo para a eficiência da AF. É indispensável que o Poder Judiciário observe e leve em consideração a existên- cia das políticas públicas de saúde a cada caso, as quais instituem direitos de forma ampla, atrelados a políticas econômicas e sociais. Seria necessário, então, que o poder público adotasse medidas capazes de proteger a saúde da população a qual se dirige. No caso do medicamento pleiteado não constar da lista do SUS, outros parâmetros deveriam ser adotados, como a indispensabilidade do medicamento para a sobrevivência do indivíduo e as opções de medicamentos com igual eficácia e custo menor.

A esmagadora maioria dos que detêm o poder de decidir acerca dos pedidos de medicamentos é favorável à sua concessão, tendo em vista sobreporem o direito à vida e à saúde a outros argumentos. Optam por proteger a vida e assim se confirma a expectativa de que as ações tenham pareceres favoráveis, muitas vezes mediante liminares, concedidas para não haver demora maior, o que não é situação segura para o paciente. Essas liminares tendem a ser cumpridas durante muito tempo, sem que seja feita uma avaliação apropriada ${ }^{1}$.

Para o Judiciário, preservar a integralidade parece estar associado à noção de consumo, vez que vêm sendo deferidas várias demandas resumidas à oferta de medicamentos, sem considerar a promoção e a prevenção a doenças e agravos. Para o indivíduo que reivindica o medicamento, o indeferimento da ação pode soar como ato desumano, como negação a seu direito à saúde. Entretanto, não há como verificar, no espaço e no tempo, pesquisas com fármacos no que concerne a aspectos teóricos da medicina, a variabilidade das práticas médicas ou taxa de sobrevivência de pacientes, pois ações judiciais abstraem a complexidade dos conflitos, reduzindo a discussão a direitos e deveres.

Também seria importante verificar se o médico que prescreve o medicamento integra a rede do SUS, sob pena de inverter sua lógica e privilegiar a aquisição de medicamentos para pacientes que não fazem uso do Sistema. $O$ direito à saúde não pode ser entendido apenas como oferta de medicamentos no mercado: deve também considerar toda a estrutura das políticas públicas de assistência à saúde, como essa saúde é produzida e simbolicamente interpretada (como direito, bem, valor econômico ou valor social). Talvez não haja outros meios de garantir o direito à saúde para toda a população senão por meio dessas políticas.

É preciso que seja viabilizada a comunicação cada vez mais ampla e bem estruturada entre as áreas jurídica e da saúde, para que possam ser 
criados espaços formais de diálogo e elaboração de políticas públicas eficazes para diminuir as ações judiciais e garantir uma melhor AF.

\section{Usuários}

Para quem necessita do medicamento, a Justiça é apenas uma forma mais rápida ou mais eficiente de obtê-lo. Para o SUS e para a União, estados e municípios, talvez esta forma não seja adequada, tendo em vista os pormenores que a envolvem. Atualmente, os usuários vêm adquirindo maior poder de organização, participando de grupos, associações, ONGs e outros, capazes de exercer maior pressão na conquista de seus direitos.

É sabido que sempre haverá pequena parcela de usuários que, por necessidade de saúde, situação clínica, resistência ou intolerância aos fármacos disponíveis, necessitarão da prescrição de drogas recém-lançadas ou ainda não disponíveis para comercialização ${ }^{1}$. Todavia, ao fazê-lo, implantam-se dificuldades na gestão da AF e em outros setores do SUS (reformas em instituições de saúde, contratação de pessoal, aquisição de equipamentos etc.).

O prazer e o bem-estar de poucos não deve suplantar o de muitos. Dessa forma, os cidadãos - profissionais e usuários - deveriam pensar, juntos, acerca da alocação de recursos, mesmo relegando desejos pessoais a segundo plano. São também necessárias ações efetivas e adequadas dos setores Judiciário e de Saúde conjuntamente, para que possam superar suas limitações (tanto quanto possível), respondendo de forma adequada às respectivas demandas.

\section{Discussão bioética}

A bioética trata das intervenções que as chamadas ciências da vida e da saúde provocam sobre a vida humana. Poder-se-ia dizer que, conforme Sanches ${ }^{10}$, a bioética estuda o comportamento moral dos seres humanos diante de toda a intervenção da biotecnociência e das ciências da saúde sobre a vida, em toda sua complexidade. Tem como um de seus objetivos a busca de benefícios e garantia da integridade do ser humano, baseada na defesa da dignidade humana ${ }^{11}$.

Em assunto tão complexo como a judicialização da medicina, percebe-se que não são poucos os dilemas. Há questionamentos sobre o fato de fornecer ou não medicamentos e a dúvida sobre como o poder público deva se posicionar, dentre outros. 0 compromisso com a vida é impulsionador de tais ques- tões, mas sabe-se que o interesse dos laboratórios farmacêuticos também influencia nessa percepção, pois travam guerra diária para conquistar maior espaço no mercado e obter maior lucro, utilizando-se do que estiver disponível no atual mundo capitalista e globalizado para impor cada nova droga - o que tem gerado crescente preocupação com questões éticas relativas às estratégias dirigidas a médicos e instituições de saúde, grupos representativos de pacientes, gestores, classe política e mídia.

Frequentemente, os laboratórios justificam suas ações agressivas de marketing pelos altos custos embutidos no desenvolvimento de novas drogas, os quais se refletiriam no preço majorado dos medicamentos no varejo. Assim, teriam que reforçar suas estratégias de comercialização, muitas vezes indiretas, sutis e sofisticadas, que nem sempre se caracterizam pelo vínculo direto entre prescrição e uso. São pressões amigáveis e jogos de influências que há muito passaram a fazer parte da cultura mercadológica dos medicamentos numa relação quase trivial com a classe médica, que com tamanho assédio sente dificuldades para manter-se longe do representante de vendas ou do material promocional ou deixar de atentar para artigos e propagandas, veiculados até mesmo nos congressos.

Para controlar tanto poder, proibições não são suficientes; há que se implantar processos de fiscalização, efetuados por órgãos competentes e conselhos de classe para monitorar e identificar com atenção e clareza as estratégias de marketing direto e indireto. Também se faz necessário implementar estratégias para evitar resultados negativos, punindo aqueles que se puserem fora dos limites éticos ${ }^{1}$.

Segundo a concepção capitalista, os lucros garantem a continuidade das pesquisas e são assegurados pela descoberta de novos fármacos ou aprimoramento dos existentes, principalmente quando de doenças que mobilizam usuários que reivindiquem fármacos capazes de trazer maior benefício e/ou controle do agravamento do mal em curto prazo - como nos casos da aids e de diversos tipos de câncer -, mostrando que o mercado se encontra propenso a inovações tecnológicas. A busca incessante pelo lucro pode, ainda, gerar omissões da indústria farmacêutica perante efeitos adversos identificados, posto que entre a vida humana e o direito ao uso de marcas muitas vezes ela opta por proteger este último.

O Brasil, com sua política de acesso universal a tratamentos de saúde, representa potencial mercado de consumo. Adicionalmente, os custos para realização de pesquisa local são relativamente baixos, mesmo considerando o rigor da normalização 
para pesquisas envolvendo seres humanos ${ }^{12}$. Os elevados padrões éticos de pesquisa no país têm por objetivo trazer avanços para a ciência e obter maiores informações sobre a eficácia de medicamentos e tratamentos de saúde.

É possível pressupor que médicos que atuaram como pesquisadores de uma nova droga venham a prescrevê-la, gerando ações judiciais para sua aquisição, o que, neste caso, denota a credibilidade e confiança que estes profissionais adquiriram no produto cujas pesquisas acompanharam. Mesmo em tais casos, a conduta deveria ser discutida eticamente, considerando-se a possibilidade de conflitos de interesses ${ }^{1}$.

O indeferimento de ação judicial para determinado medicamento pode ser interpretado como uma negativa do direito à saúde imposta ao cidadão. Talvez esse enfoque possa estar equivocado, pois o direito à saúde não se resume apenas à política de ofertas de medicamentos, numa visão reducionista que veria a doença como foco de ações curativas e paliativas. A existência e a atuação do SUS se propõem a ir mais além, oferecendo tratamento à população em diversos níveis de complexidade. As ações de promoção e prevenção, por exemplo, encontramse mais focadas em campanhas, estando o uso de fármacos praticamente restrito às ações de assistência à saúde ${ }^{2}$.

Assim, a manutenção da equidade e da integralidade da saúde pode estar sendo vista pelo poder público como se os fármacos fossem o único caminho no combate a doenças e agravos, sem ponderar as políticas públicas de saúde que envolvem os direitos sociais. Pode-se estar decidindo apenas politicamente e, dessa forma, inibindo a equidade. Ademais, tais demandas, sem que haja tempo ou estrutura para avaliar detalhadamente o caso antes do deferimento, criam dificuldades à gestão do SUS. Se o pressuposto for o de atendimento incontinenti aos processos judiciais, o direito à saúde estará sendo garantido, mas as políticas públicas de saúde estarão relegadas a segundo plano.

A assistência à saúde deve ser exercida de modo a permitir que todos tenham respeitada sua autonomia, o que requer reflexão crítica e ética acerca dos recursos disponíveis. Há que se permanecer atento para que a vulnerabilidade pessoal não venha a se tornar vulnerabilidade social - esta última contendo fatores que levam ao decréscimo do bem-estar de todos, expondo famílias e comunidades a riscos. Não se pode esquecer que o direito do cidadão à garantia de acesso aos medicamentos também é ferramenta de controle sobre o Estado, evitando a negligência.
Se o Judiciário defere o fornecimento de medicamentos constantes nas listas do SUS, pelo fato de não estarem disponíveis nas unidades de saúde ou nas farmácias hospitalares, isso se constitui em demanda plenamente pertinente. No entanto, o mesmo não ocorre em se tratando de medicamentos ausentes dessas listas ou mesmo de alguns sem registro na Anvisa, quando efeitos colaterais eventuais ainda não puderam ser avaliados e muitas vezes o próprio usuário desconhece os riscos a que está submetido. Em síntese, o conhecimento acerca dos critérios de seleção de medicamentos constantes da $\mathrm{AF}$, bem como da assistência à saúde, deve ser disseminado entre os profissionais de saúde e os membros do Judiciário, reconhecendo que a sociedade não pode mais abdicar da garantia de seus direitos.

Mas é necessário que sejam apontados os paradoxos que envolvem as ações judiciais referentes à aquisição de medicamentos. O conhecimento e a conscientização dos profissionais poderiam contribuir para reduzir as demandas judiciais sem comprometer o direito à saúde. O maior diálogo entre secretarias de saúde e tribunais viabilizaria uma rica troca de informações, benéfica a todos, facilitando as ações das primeiras quanto à dispensação de medicamentos e dos últimos, quanto às ações judiciais.

Muitas vezes, a sociedade se mostra mais propensa a recorrer à Justiça do que ciente das atribuições do SUS. O cidadão parte em busca da equidade, mas esta diz respeito a ele e a todos ou usuários do Sistema simultaneamente, numa contínua busca de cooperação social entre todos, em sua condição de livres e de iguais. Se lhe é concedido o direito de obter certo medicamento, para que houvesse a equidade seria preciso que todos que necessitassem da mesma prescrição fossem atendidos; mais ainda, seria preciso atender a todos os que necessitassem de qualquer medicamento, até mesmo sem a intervenção do Judiciário. Há que se ter alguns cuidados, portanto, para que essa judicialização não venha a ampliar a dimensão de conflitos sociais já em curso.

Medicamentos direcionados a pacientes em fase terminal - que não são os que mais os reivindicam - demandam especial atenção aos efeitos colaterais possíveis, bem como às interações medicamentosas. O paciente terminal já está, por si, em clara condição de vulnerabilidade e, por isso, devem ser envidados esforços para mantê-lo em condições de conforto físico e emocional, considerando a irreversibilidade do caso.

Na continuidade de tal reflexão, deve ser considerado o fato de que as ciências da saúde ainda não se encontrem capazes de vencer a morte, mas 
apenas de adiá-la. Morre-se por ser mortal e não por adoecer. Ao lançar mão da judicialização da medicina, este ato deve ser revestido da mais alta comiseração para com aquele cuja vida está para terminar, não o submetendo a procedimentos invasivos e dolorosos não necessários apenas para adiar uma morte anunciada. Pacientes em estágio terminal necessitam de cuidados, mais que de cirurgias, denotando o respeito e o carinho da equipe para com ele e familiares. Se nesses parâmetros a intervenção judicial for entendida como procedimento supérfluo, ela deverá ser evitada, minimizando o desgaste emocional dos envolvidos. Nos casos de doenças crônicas ou agudas em que se lança mão da judicialização da medicina, outros fatores terão que ser considerados.

O poderio biotecnológico avança a passos largos, impondo a todos suas condições; o poder exercido pela área da saúde impera ante o público em geral. Antes do deferimento ou indeferimento de processos, é necessário que se perceba que a judicialização da medicina acaba por agir em consonância com a chamada "medicalização da saúde" fenômeno no qual medicamentos podem ser vistos como mercadoria e seu consumo como uma pretensa forma de felicidade e de saúde ${ }^{13}$. No processo saúde-doença, esta vai concretizando o desejo capitalista de solução para tudo - se possível até para a morte.

$\mathrm{Na}$ sociedade atual, fala-se em saúde por toda parte: em busca da satisfação baseada principalmente em modelos veiculados pela mídia, o ser humano se expõe a bisturis, alimentos, tratamentos, exercícios e cosméticos, no afã interminável de felicidade e bem-estar ${ }^{14}$. Numa sociedade que vive com a aparência jovial negando a idade biológica, a saúde passa a ser um meio e um fim em si mesma; a dor, o sofrimento, a felicidade e a morte passam por radicais modificações, nem sempre positivas; pessoas se acostumaram a fazer uso de medicamentos por absoluta intolerância à frustração, ao enfrentar as mais básicas situações que outrora eram resolvidas deixando simplesmente que suas emoções viessem à tona. Se antes a dor era acolhida com naturalidade, hoje é preciso exilá-la a qualquer custo; é necessário não estar depressivo, ansioso ou portar emoções fortes e se desvencilhar da dor, o que frequentemente envolve o uso de medicamentos que "normalizam" comportamentos e eliminam sintomas de sofrimento, sem lhes buscar o significado.

Numa sociedade identificada pela analgesia, a dor é frequentemente despojada de sua dimensão subjetiva; o sofrimento é despido de sua dimensão íntima e pessoal e transformado em problema técnico; o paciente é transformado em consumidor de cuidados sem que haja maiores preocupações com seu sofrimento psíquico ${ }^{15}$. Desse modo, é preciso que ao diagnóstico se siga a medicalização, para que qualquer dor deixe de ser sentida, mesmo impondo métodos de analgesia cada vez mais fortes e invasivos, muitas vezes capazes de provocar cada vez mais efeitos adversos. Medicamentos como bens de consumo são tratados sob a lógica comercial. A medicalização da existência faz da vida uma doença e consome-se o que está sendo ofertado, não que necessariamente solucione o problema. Nesse contexto, o apelo ao cuidado com a saúde se confunde com o apelo ao consumo, do qual todos somos vítimas. A medicalização faz da saúde um bem de consumo como qualquer outro e a indústria farmacêutica age como qualquer outra indústria, colocando seus produtos no mercado com intenção de lucro.

Assim estruturada, a sociedade jamais se contentará em utilizar medicamentos já consagrados em seus efeitos; estará sempre em busca de outros pertencentes à nova geração, capazes de livrá-la dos mais diversos problemas, trazer saúde e, quiçá, vida eterna. Despesas com saúde, dessa forma, não cessarão de crescer: pacientes-consumidores se mostrando cada vez mais intolerantes ao mal-estar, enquanto médicos, imbuídos de saber e poder biotecnológico, com a certeza de estar oferecendo a seus pacientes o medicamento mais poderoso, conforme Ihes fizeram acreditar. Expostos às mesmas relações de poder, criam-se em ambos a obsessão pela saúde, por uma via tecnicista.

$\mathrm{Na}$ verdade, seria preciso maior acolhimento de todos para com todos, a fim de que dores emocionais deixem de se refletir no corpo físico e possam ser expostas ao mundo real. O corpo, foco de sacrifícios contínuos, deveria receber atenção menos massificante e mais individualizada, a fim de reverter a avidez contínua e infindável por medicamentos que o deixem feliz. A falta de disposição para entender a si mesmo e ao mundo acaba por relegar a felicidade ao abandono, substituída por um composto químico, manipulado em laboratório e vendido em farmácias.

Também a efetiva ação de um órgão, tal como uma Comissão Nacional de Bioética, poderia ser de suma importância para a satisfação de todas as partes envolvidas, para o equilíbrio orçamentário e para uma boa prática e maior segurança no uso de medicamentos. Tal órgão poderia agir com vistas ao ordenamento de situações-problema, analisadas conjuntamente à luz da bioética, do Judiciário e das 
profissões de saúde, além de outras que pudessem se fazer presentes.

Esclareça-se que não há, aqui, a pretensão de julgar a legitimidade de tais práticas, mas de discutilas, buscando-lhes a razão. Faz-se necessário resgatar valores inerentes a uma vida boa, à qualidade de vida física, mental e espiritual, em lugar de vislumbrar somente o aspecto estético do corpo físico. Uma vida humana boa e digna embasa-se em valores que ultrapassam as prateleiras de medicamentos e culmina em bem-estar mais amplo, em convívio social satisfatório, em atendimento a outras grandes necessidades que se encontram mais além de manifestações álgicas apresentadas no corpo e pelo corpo.

\section{Considerações finais}

O processo de judicialização da medicina vem adquirindo cada vez mais vulto dentro da sociedade brasileira, tomando-se por base muitos dos fatores ora apontados, quer referentes ao próprio Poder Judiciário ou ao SUS, nas pessoas de seus profissionais, usuários ou ambos. É de se esperar que a corrida desenfreada aos processos judiciais para obter medicamentos não deverá ter condições para se sustentar ao longo prazo, talvez nem mesmo a médio; outras necessidades dos usuários do SUS provavelmente deixarão (cada vez mais) de ser atendidas, o que certamente reverterá em um efeito negativo para todos.

Atualmente, quando o mundo parece girar em velocidade cada vez maior e os acontecimentos se sucedem sem que haja tempo para revê-los ou refletir sobre eles, a humanidade se torna cada vez mais vulnerável e a vida de cada um, carente de sentido. Esse sentido que é buscado por todos, a partir de algum momento de suas existências, particularmen- te nas situações de intenso sofrimento e de morte, levando ao questionamento e à reflexão. Os que decidem agir conscientemente de acordo com o que Ihes faça sentido estarão certamente assumindo uma postura eticamente correta, desde que essa ação não venha a ser prejudicial a outros ${ }^{15}$.

Assim também devem ser vistas as decisões tomadas pelos juristas: decisões com caráter ético têm que contemplar a complexidade da vida humana. É necessário, assim, que uma solução compartiIhada por todos seja adotada. Não é possível deixar de garantir a atenção integral ao cidadão, nem tampouco deixar de ver a saúde como direito.

Da mesma forma, é preciso garantir a esse cidadão que os medicamentos utilizados serão seguros e eficazes, com relação custo-efetividade favorável, de acordo com a melhor evidência científica disponível. Faz-se mister, portanto, a discussão do assunto, quiçá com a criação de um canal de comunicação entre saúde e Justiça, viabilizando talvez pareceres técnicos específicos para cada caso, com esforços de ambos os lados em prol de soluções viáveis. É preciso que as distorções causadas pela aquisição de medicamentos por ordem jurídica sejam mínimas, em situações nas quais não haja realmente outra opção de medicamento capaz de beneficiar aquele paciente, trazendo-lhe conforto, bem como a redução de processos de dor e sofrimento.

Por fim, desvinculando-se do caráter apenas biológico da doença e trazendo à luz algumas das variáveis de cunho psicológico, social e econômico, que se fizesse possível uma reflexão acerca do que significa para cada indivíduo o pedido e a obtenção das medicações por via judiciária. Com isso, talvez fossem revelados pontos importantes e descobertas interessantes viessem à tona. Questões pessoais e qualidade de vida poderiam estar, dessa forma, preservadas.

\section{Referências}

1. Brasil. Ministério da Saúde. O remédio via justiça: um estudo sobre o acesso a novos medicamentos e exames em HIV/Aids no Brasil por meio de ações judiciais. Brasília: Ministério da Saúde; 2005.

2. Machado MAA, Acurcio FA, Brandão CMR, Faleiros DR, Guerra Jr A, Cherchiglia ML et al. Judicialização do acesso a medicamentos no Estado de Minas Gerais, Brasil. [Internet]. Rev. saúde pública. 2011 (acesso 3 ago. 2011);45(3):590-8. Disponível: http://www.scielo.br/scielo. php?pid=S0034-89102011000300018\&script=sci_arttext

3. Brasil. Ministério da Saúde. Portaria $n^{\circ}$ 3.916, de 30 de outubro de 1998. Política nacional de medicamentos. [Internet]. Brasília: Ministério da Saúde; 1998 (acesso 3 ago. 2011). Disponível: http://bvsms.saude.gov.br/bvs/saudelegis../gm/1998/prt3916_30_10_1998.html

4. Brasil. Ministério da Saúde. Relação nacional de medicamentos essenciais - Rename. [Internet]. Brasília: Ministério da Saúde; 2012 (acesso 15 jan. 2012). Disponível: http://portal.saude.gov.br/ portal/arquivos/pdf/CONITECANEXOSRENAME.pdf 
5. Medeiros M, Diniz D, Schwartz IVD. Tese da judicialização da saúde pelas elites: os medicamentos para mucopolissacaridose. Ciênc. saúde coletiva. 2013 (acesso 3 jun. 2013);18(4):1079-1088. Disponível: http://www.scielo.br/pdf/csc/v18n4/22.pdf

6. Andrade EIG, Machado CD, Faleiros DR, Szuster DAC, Guerra Jr AA, Silva GD et al. A judicialização da saúde e a política nacional de assistência farmacêutica no Brasil: gestão da clinica e medicalização da justiça. [Internet]. Rev Med Minas Gerais. 2008 (acesso 3 ago. 2011);18(4 Suppl):546-50. Disponível: <http://rmmg.medicina.ufmg.br/index.php/rmmg/article/viewArticle/102>

7. Messeder AM, Castro CGSO, Luiza VL. Mandados judiciais como ferramenta para a garantia de acesso a medicamentos no setor público: a experiência do Estado do Rio de Janeiro, Brasil. [Internet]. Cad. Saúde Pública. 2005 (acesso 3 ago. 2011);21(2):525-34. Disponível: http://www. scielosp.org/pdf/csp/v21n2/19.pdf

8. Pepe VLE, Ventura M, Sant'ana JMB, Figueiredo TA, Souza VR, Simas L et al. Caracterização das demandas judiciais de fornecimento de medicamentos "essenciais" no Estado do Rio de Janeiro, Brasil. [Internet]. Cad. Saúde Pública. 2010 (acesso 3 ago. 2011);26(3):461-71. Disponível: http://www.scielosp.org/pdf/csp/v26n3/04.pdf

9. Borge $D C L$, Ugá MAD. As ações individuais para o fornecimento de medicamentos no âmbito do SUS: características dos conflitos e limites para a atuação judicial. [Internet]. Rev. direito sanit. 2009 (acesso 3 ago. 2011);10(1):13-38. Disponível: http://www6.ensp.fiocruz.br/repositorio/ resource/355560

10. Sanches MA. Bioética: ciência e transcendência. São Paulo: Loyola; 2004.

11. Fischer JK, Araújo LRT, Wiegand SCB, D’Espíndula TS. Cadernos de tanatologia. Curitiba: Unificado: 2007. (Coletânea ConexãoPsi - Série Técnica).

12. Brasil. Conselho Nacional de Saúde. Resolução n 196, de 10 de outubro de 1996. Dispõe sobre as diretrizes e normas regulamentadoras de pesquisa envolvendo seres humanos. Brasília: Ministério da Saúde; 1996.

13. Barros JAC. Ampliando espaços para a medicalização: instrumento para desfrute de melhores níveis de saúde? In: Caponi S, Verdi M, Brzozowski FS, Hellmann F, organizadores. Medicalização da vida: ética, saúde pública e indústria farmacêutica. Florianópolis: Unisul; 2010. p. 85-9.

14. D'Espíndula TCAS. O paradoxo do cuidado da vida e do controle do patológico em Michel Foucault [dissertação]. Curitiba: Universidade Católica do Paraná; 2011.

15. D’Espíndula TCAS, Santos KS. Dor e sofrimento: uma reflexão bioética [monografia]. Curitiba: Universidade Católica do Paraná; 2008.

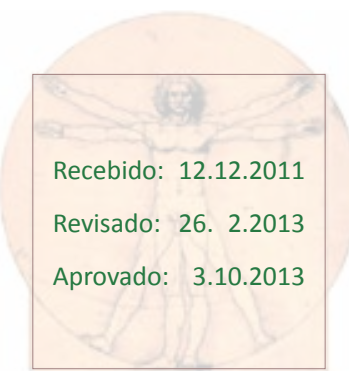

